\title{
Uptake of Recommendations for Posttreatment Cancer-Related Fatigue Among Breast Cancer Survivors
}

\author{
Antonio Di Meglio, MD, $\mathrm{PhD}^{1}$; Cecile Charles, $\mathrm{PhD}^{2,3}$; Elise Martin, $\mathrm{PhD}^{1}$; Julie Havas, $\mathrm{MSc}^{1}$; Arnauld Gbenou, MSc ${ }^{1}$; \\ Jean-Daniel Flaysakier, $\mathrm{MD}^{1}$; Anne-Laure Martin, $\mathrm{PhD}^{4}$; Sibille Everhard, $\mathrm{PhD}^{4}$; Enora Laas, $\mathrm{MD}^{5}$; Nicolas Chopin, $\mathrm{MD}^{6}$; \\ Laurence Vanlemmens, $\mathrm{MD}^{7}$; Christelle Jouannaud, $\mathrm{MD}^{8}$; Christelle Levy, MD ; Olivier Rigal, $\mathrm{MD}^{10}$; Marion Fournier, $\mathrm{MD}^{11}$; \\ Patrick Soulie, MD ${ }^{12}$; Florian Scotte, MD²; Barbara Pistilli, MD'; Agnes Dumas, PhD ${ }^{13}$; Gwenn Menvielle, PhD ${ }^{14}$; \\ Fabrice André, MD, $\mathrm{PhD}^{1}$; Stefan Michiels, $\mathrm{PhD}^{1}$; Sarah Dauchy, $\mathrm{MD}^{2}$; and Ines Vaz-Luis, MD, $\mathrm{PhD}^{1}$
}

\begin{abstract}
Background: Physical activity (PA) and psychosocial interventions are recommended management strategies for cancer-related fatigue (CRF). Randomized trials support the use of mind-body techniques, whereas no data show benefit for homeopathy or naturopathy. Methods: We used data from CANTO (ClinicalTrials.gov identifier: NCT01993498), a multicenter, prospective study of stage I-III breast cancer (BC). CRF, evaluated after primary treatment completion using the EORTC QLQC30 (global CRF) and QLQ-FA12 (physical, emotional, and cognitive dimensions), served as the independent variable (severe [score of $\geq 40$ / $100]$ vs nonsevere). Outcomes of interest were adherence to PA recommendations ( $\geq 10$ metabolic equivalent of task [MET] h/week [GPAQ16]) and participation in consultations with a psychologist, psychiatrist, acupuncturist, or other complementary and alternative medicine (CAM) practitioner (homeopath and/or naturopath) after CRF assessment. Multivariable logistic regression examined associations between CRF and outcomes, adjusting for sociodemographic, psychologic, tumor, and treatment characteristics. Results: Among 7,902 women diagnosed from 2012 through 2017, 36.4\% reported severe global CRF, and 35.8\%, 22. $6 \%$, and $14.1 \%$ reported severe physical, emotional, and cognitive CRF, respectively. Patients reporting severe global CRF were less likely to adhere to $\mathrm{PA}$ recommendations $(60.4 \%$ vs $66.7 \%$; adjusted odds ratio [aOR], 0.82 ; $95 \% \mathrm{Cl}, 0.71-0.94 ; P=.004$ ), and slightly more likely to see a psychologist (13.8\% vs 7.5\%; aOR, 1.29; $95 \% \mathrm{Cl}, 1.05-1.58 ; P=.014)$, psychiatrist $(10.4 \%$ vs $5.0 \%$; aOR, $1.39 ; 95 \% \mathrm{Cl}, 1.10-1.76 ; P=.0064)$, acupuncturist $(9.8 \%$ vs 6 . $5 \%$; aOR, $1.46 ; 95 \% \mathrm{Cl}, 1.17-1.82 ; P=.0008)$, or CAM practitioner (12.5\% vs 8.2\%; aOR, 1.49; 95\% Cl, 1.23-1.82; $P<.0001)$. There were differences in recommendation uptake by $\mathrm{CRF}$ dimension, including that severe physical CRF was associated with lower adherence to PA (aOR, 0.74; 95\% Cl, 0.63-0. 86; $P=.0001$ ) and severe emotional CRF was associated with higher likelihood of psychologic consultations (aOR, 1.37; 95\% Cl, 1.06-1.79; $P=.017$ ). Conclusions: Uptake of recommendations to improve CRF, including adequate PA and use of psychosocial services, seemed suboptimal among patients with early-stage $\mathrm{BC}$, whereas there was a nonnegligible interest in homeopathy and naturopathy. Findings of this large study indicate the need to implement recommendations for managing CRF in clinical practice.
\end{abstract}

J Natl Compr Canc Netw, doi: 10.6004/jnccn.2021.7051 Published online February 7, 2022

See JNCCN.org for supplemental online content.

\section{Background}

Improved cure rates and prolonged survival after breast cancer (BC) treatment have resulted in an increasing population of survivors facing varying degrees of chronic adverse effects and treatment-related symptoms. ${ }^{1-4}$ Among these, cancer-related fatigue (CRF) is extremely common and persistent. ${ }^{5-8}$ Compared with fatigue experienced by individuals without cancer, CRF is described as more intense, distressing, and less responsive to rest. ${ }^{9-11}$ Its manifestations can include generalized weakness, decreased motivation and interest to engage in usual activities or emotional lability, and diminished concentration or attention. ${ }^{12-14} \mathrm{CRF}$ is a multifactorial symptom. Younger age, lower socioeconomic status, psychologic distress, concomitant symptoms, unhealthy behaviors such as tobacco use, inactivity, and higher body mass index (BMI) are often associated with higher risk of $\mathrm{CRF}^{8,12}$ Multiple life domains are negatively impacted by CRF because it can interfere with normal functioning, mood, social relationships, work, sleep, and daily activities. ${ }^{7,10,15,16}$

Building on mechanisms and pathophysiology underpinning CRF, particularly an increased expression of genes encoding proinflammatory cytokines or other mediators of immunologic activation, ${ }^{12,17-21}$ some treatment strategies were tested and are now recommended. Meta-analyses, systematic reviews, and randomized trials showed that initiating or maintaining adequate levels of physical activity

${ }^{1}$ INSERM Unit 981, Molecular Predictors and New Targets in Oncology, Gustave Roussy, Villejuif; ${ }^{2}$ Département de Soins de Support, Gustave Roussy, Villejuif; ${ }^{3}$ Laboratoire de Psychopathologie et Processus de Santé, Université Paris Descartes-Sorbonne Paris Cité, Boulogne-Billancourt; ${ }^{4}$ UNICANCER, Paris; ${ }^{5}$ Medical Oncology, Institut Curie, Paris; ${ }^{6}$ Medical Oncology, Centre Léon Berard, Lyon; ${ }^{7}$ Medical Oncology, Centre Oscar Lambret, Lille; ${ }^{8}$ Medical Oncology, Institut Jean Godinot, Reims; ${ }^{9}$ Medical Oncology, Centre François Baclesse, Caen; ${ }^{10}$ Medical Oncology, Centre Henri Becquerel, Rouen; ${ }^{11}$ Medical Oncology, Institut Bergonié, Bordeaux; ${ }^{12}$ Medical Oncology, Institut de Cancérologie de L'ouest-Paul Papin, Angers; ${ }^{13}$ Universite de Paris, ECEVE UMR 1123 INSERM, Paris; and ${ }^{14}$ Institut Pierre Louis d'Épidémiologie et de Santé Publique, Sorbonne Université, INSERM, Paris, France. 
(PA) can improve CRF for BC survivors, both on treatment and in the posttreatment setting, by acting on the modulation of inflammatory mediators. ${ }^{22-26}$ Given its multifactorial etiology and strong link with psychologic distress level, the effect of PA on CRF may also be exerted through an action on self-esteem and depressive status. ${ }^{27}$ Engaging in an active lifestyle and sport activities can help patients with cancer improve global functionality and facilitate cognitively and psychologically demanding tasks such as health-related decision-making processes, empowering their ability to manage symptoms such as CRF. PA was suggested to work on specific skills such as improving problem-solving schemes, training attention and coping, strengthening strategy, tactics and creativity, and enhancing self or introspective processes. ${ }^{28}$ These skills can be adapted from PA experiences and transferred to a cancer and symptom management context. ${ }^{29,30}$ Reductions in CRF were also observed with psychosocial therapy that included cognitive behavioral or psychoeducational approaches targeting nonadaptive thoughts, such as catastrophizing. ${ }^{12,26,31}$

Mind-body interventions, focused on the interactions among brain, mind, body, and behavior, ${ }^{32}$ include a variety of practices, such as acupuncture, yoga, and mindfulnessbased meditation, that have also been tested to treat $\mathrm{CRF}^{26,33}$ Data from several reviews and clinical trials suggested that acupuncture may be beneficial for persistent $\mathrm{CRF}^{33-40}$ To date, there are no data showing benefits of other complementary and alternative medicine (CAM) strategies, such as homeopathy or naturopathy, in the posttreatment setting for BC survivors. ${ }^{26,33,41}$

Regular screening, assessment, education, and appropriate treatment of CRF are considered priorities in modern survivorship care. PA and referral to psychosocial service providers are strongly encouraged to reduce CRF, especially for patients reporting at least moderate-to-severe $\mathrm{CRF}^{26,33}$ The NCCN Clinical Practice Guidelines in Oncology (NCCN Guidelines) for CRF include PA and psychosocial interventions as category 1 recommendations for CRF in patients after treatment (high-level evidence, uniform NCCN consensus that the intervention is appropriate). ${ }^{33}$ Nevertheless, large-scale data on the real-world use of recommended strategies for CRF are lacking. We aimed to describe the uptake of strategies that can help reduce CRF among patients with early-stage $\mathrm{BC}$ who have completed primary treatment.

\section{Methods}

\section{Data Source}

This study used data from CANTO (ClinicalTrials.gov identifier: NCT01993498); study procedures were described previously. ${ }^{42}$ Briefly, CANTO is a prospective, multicentric cohort of women with stages I-III BC designed to study BC toxicities. Patients exit CANTO at any BC recurrence (other than local) or second cancers. We used data that were collected at diagnosis and during the first and second post-primary treatment completion visits. Primary treatment included surgery, chemotherapy, and/or radiation therapy. Endocrine and anti-HER2 treatment could be ongoing. All participants provided informed consent, and the study was approved by the national regulatory and ethics committee (ID-RCB:2011-A01095-36,11-039).

\section{Study Cohort}

In the present analysis, we used data until the second posttreatment visit among 9,595 patients who entered CANTO from 2012 to 2017. Women with CRF assessment at the first posttreatment visit $(n=7,902 ; 82.4 \%)$ were included (Figure 1).

\section{Variables of Interest}

\section{Outcome Variables}

Outcomes of interest were assessed at the second posttreatment visit ( $\sim$ year after primary treatment completion).

\section{Physical Activity}

The WHO Global Physical Activity Questionnaire (GPAQ)-16 was used to assess sedentary behavior and the duration and intensity of $\mathrm{PA}^{43}$ As per WHO recommendations, patients reporting $\geq 10$ metabolic equivalents of task (MET) h/week qualified as sufficiently active (corresponding to $150 \mathrm{~min} /$ week of moderate-intensity PA or $75 \mathrm{~min} /$ week of vigorous $\mathrm{PA}$, or an equivalent combination), ${ }^{43}$ whereas patients engaging in $<10 \mathrm{MET} h$ /week qualified as insufficiently active. Categories for change in PA between the first and second posttreatment visits were therefore "maintained or increased" PA (sufficiently active before and after or insufficiently active before and sufficiently active after) versus "decreased or persistently insufficient” PA (sufficiently active before and insufficiently active after or insufficiently active before and after).

\section{Consultations With Other Healthcare Providers}

Per CANTO protocol, patients were systematically asked by trained clinical research nurses during health examinations if and how many times they had consulted with one of the following providers since the first posttreatment visit: psychologist, psychiatrist, acupuncturist, or other CAM practitioner (homeopath and/or naturopath). Therefore, these types of consultations were explored as outcomes.

\section{Independent Variable}

CRF was reported at the first posttreatment visit $(\sim 3-6$ months after treatment completion) using the validated French versions of the EORTC Core Quality of Life Questionnaire (QLQ-C30) and QLQ-FA12. ${ }^{42,44-48} \mathrm{CRF}$ was categorized as severe if patients scored $\geq 40$ out of 100 , based on previously defined thresholds of clinical importance ${ }^{8,49}$ 


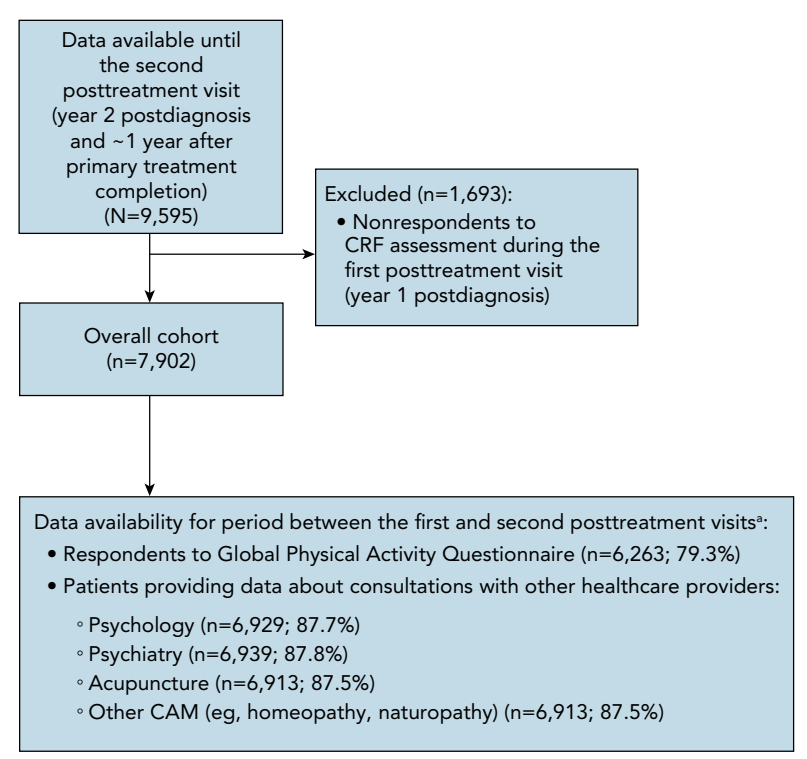

Figure 1. CONSORT diagram of patient population.

Abbreviations: CAM, complementary and alternative medicine; CRF, cancerrelated fatigue.

aPatients providing data on physical activity and healthcare consultations were more likely to be better educated and enrolled from larger CANTO centers, although no major differences were present compared with nonrespondents.

(details provided in supplemental eAppendix 1, available with this article at JNCCN.org).

\section{Covariates}

Other variables were categorized as per Table 1.

\section{Statistical Analysis}

Cohort characteristics were summarized for the whole cohort and described by global CRF status at first posttreatment visit (severe vs nonsevere). Uptake of PA recommendations and other consultations was then analyzed. We used multivariable logistic regression models to evaluate the odds of maintaining or increasing PA and of participating in other consultations between the first and second posttreatment visits according to CRF status as reported at the first posttreatment visit, adjusting for age, BMI, comorbidities, anxiety and depression, education, income, tumor stage and subtype, breast and axillary surgery, chemotherapy, and center volume. Two sets of models were fit by outcome: (1) global CRF, and (2) physical, emotional, and cognitive CRF dimensions as independent variables. We used a distinct regression model for each outcome. Variations in sedentary time (continuous) were assessed using multivariable random-effect mixed models, adjusted for CRF, time, CRF-by-time interaction, and covariates.

Sensitivity analyses were performed as follows: (1) factors potentially influencing use of specific strategies (affecting ability to participate in PA or prompting other consultations) were included, particularly (a) patient-reported outcomes
(PROs) such as pain (EORTC QLQ-C30), systemic therapy adverse effects, and arm symptoms (EORTC QLQ-BR23), and (b) clinician-documented toxicities such as arthralgia, myalgia, and neuropathy (CTCAE version 4.0); (2) CRF was modeled as continuous; and (3) endocrine and anti-HER2 therapy were included after removing subtype.

We hypothesized that women experiencing severe CRF would rely more heavily on strategies that are highly recommended to relieve this symptom (ie, PA and mental healthcare services delivering psychosocial interventions [NCCN category 1 recommendation $]^{33}$ ). We also hypothesized a substantial diversity in the way these strategies are integrated in the care pathway, due to variance in circumstances and resources..$^{33}$ Statistical significance was defined with a 2-sided $P$ value of 0.017 to accommodate some multiple comparisons among primary outcomes of interest (ie, PA, psychologic, and psychiatric consultations). Acupuncture and CAM service use were considered exploratory outcomes. Statistical analysis was performed using SAS 9.4 (SAS Institute Inc).

\section{Results}

\section{Cohort Characteristics}

Among the whole cohort, the mean [SD] global CRF score was 36.2 [25.7] and 2,873 patients (36.4\%) reported severe global CRF (score $\geq 40)^{8}$ during the first posttreatment visit. Patients with severe CRF were younger and had higher BMI, worse anxiety and/or depression scores, lower education level and/or income, worse PROs, and worse treatment-related toxicities than patients without severe CRF (Table 1). Patients reported mean [SD] scores of 33.2 [24.3] for physical, 23.3 [26.5] for emotional, and 18.0 [23.4] for cognitive CRF, whereas severe CRF was prevalent among $35.8 \%(n=2,814), 22.6 \%(n=1,776)$, and $14.1 \%(\mathrm{n}=1,107)$ for each dimension, respectively (supplemental eTable 1).

\section{Global CRF and Recommendations Uptake}

Table 2 and supplemental eTable 1 describe exposure to PA and use of consultations with other healthcare providers between first and second posttreatment visits by global CRF status and by CRF dimension, respectively. Overall, 4,035 patients (64.4\%) met recommendations on PA between the first and second posttreatment visits (Table 2). Patients with severe global CRF at the first visit had lower odds of meeting PA recommendations between first and second visits $(60.4 \%$ vs $66.7 \%$; adjusted odds ratio [aOR], 0.82; 95\% CI, 0.71-0.94; $P=.004)$ than those with nonsevere CRF (Table 3). Particularly, the proportion of patients maintaining sufficient levels of PA was lower among severely fatigued patients $(44.0 \%$ vs $53.7 \%$ among nonseverely fatigued) (Table 2). Accordingly, sedentary time significantly increased for patients with severe CRF who were sufficiently active at the first visit, but not among 


\section{Table 1. Cohort Characteristics of Participants With Posttreatment CRF Data}

\begin{tabular}{|c|c|c|c|c|}
\hline \multirow[b]{2}{*}{ Characteristic } & \multirow[b]{2}{*}{$\begin{array}{l}\text { Whole Cohort } \\
\text { n (\%) }\end{array}$} & \multicolumn{3}{|c|}{ CRF } \\
\hline & & $\begin{array}{l}\text { Nonsevere } \\
\text { n (\%) }\end{array}$ & $\begin{array}{l}\text { Severe } \\
\text { n (\%) }\end{array}$ & $P$ Value ${ }^{\text {a }}$ \\
\hline Total & $7,902(100)$ & $5,029(63.6)$ & $2,873(36.4)$ & \\
\hline Age at diagnosis, y & & & & $<.0001$ \\
\hline Mean [SD] & $56.2[11.2]$ & $57.2[11.1]$ & $54.4[11.2]$ & \\
\hline Missing & - & - & - & \\
\hline Body mass index, $\mathrm{bg} / \mathrm{m}^{2}$ & & & & $<.0001$ \\
\hline Mean [SD] & $26.0[5.4]$ & $25.7[5.1]$ & $26.6[5.9]$ & \\
\hline Missing & 334 & 223 & 111 & \\
\hline Initial level of PA, ${ }^{b}$ MET h/wk & & & & $<.0001$ \\
\hline Median (Q1-Q3) & $16.0(4.0-41.3)$ & $18.0(5.0-42.0)$ & $14.0(0.0-37.3)$ & \\
\hline Missing & 76 & 44 & 32 & \\
\hline Menopausal status & & & & $<.0001$ \\
\hline Premenopausal & $2,893(37.3)$ & $1,670(33.8)$ & $1,223(43.5)$ & \\
\hline Postmenopausal & $4,858(62.7)$ & $3,267(66.2)$ & $1,591(56.5)$ & \\
\hline Missing & 151 & 92 & 59 & \\
\hline Charlson comorbidity index score & & & & .0027 \\
\hline 0 & $5,859(80.6)$ & $3,785(81.6)$ & $2,074(78.7)$ & \\
\hline$\geq 1$ & $1,414(19.4)$ & $853(18.4)$ & $561(21.3)$ & \\
\hline Missing & 629 & 391 & 238 & \\
\hline Anxiety $^{b}$ & & & & $<.0001$ \\
\hline Non-case (score 0-7) & $4,354(55.5)$ & $3,285(65.8)$ & $1,069(37.6)$ & \\
\hline Doubtful (score 8-10) & $1,886(24.1)$ & $1,083(21.7)$ & $803(28.2)$ & \\
\hline Case (score 11-21) & $1,598(20.4)$ & $626(12.5)$ & $972(34.2)$ & \\
\hline Missing & 64 & 35 & 29 & \\
\hline Depression $^{b}$ & & & & $<.0001$ \\
\hline Non-case (score 0-7) & $6,362(81.2)$ & $4,564(91.3)$ & $1,798(63.3)$ & \\
\hline Doubtful (score 8-10) & $941(12.0)$ & $337(6.7)$ & $604(21.2)$ & \\
\hline Case (score 11-21) & $535(6.8)$ & $95(1.9)$ & $440(15.5)$ & \\
\hline Missing & 64 & 33 & 31 & \\
\hline Highest education level & & & & .482 \\
\hline Primary school & $1,075(14.5)$ & $684(14.4)$ & $391(14.6)$ & \\
\hline High school & $3,470(46.8)$ & $2,192(46.3)$ & $1,278(47.6)$ & \\
\hline College degree or higher & $2,875(38.7)$ & $1,858(39.2)$ & $1,017(37.9)$ & \\
\hline Missing & 482 & 295 & 187 & \\
\hline Monthly household income & & & & $<.0001$ \\
\hline$<€ 3,000$ & $3,804(55.4)$ & $2,295(52.8)$ & $1,509(59.8)$ & \\
\hline$\geq € 3,000$ & $3,062(44.6)$ & $2,049(47.2)$ & $1,013(40.2)$ & \\
\hline Missing & 1,036 & 685 & 351 & \\
\hline Cancer stage $^{c}$ & & & & $<.0001$ \\
\hline 1 & $3,966(50.2)$ & $2,638(52.5)$ & $1,328(46.3)$ & \\
\hline ॥ & $3,141(39.8)$ & $1,921(38.2)$ & $1,220(42.5)$ & \\
\hline III & $789(10.0)$ & $468(9.3)$ & $321(11.2)$ & \\
\hline Missing & 6 & 2 & 4 & \\
\hline
\end{tabular}




\section{Table 1. Cohort Characteristics of Participants With Posttreatment CRF Data (cont.)}

\begin{tabular}{|c|c|c|c|c|}
\hline \multirow[b]{2}{*}{ Characteristic } & \multirow[b]{2}{*}{$\begin{array}{l}\text { Whole Cohort } \\
\text { n (\%) }\end{array}$} & \multicolumn{3}{|c|}{$\mathrm{CKr}$} \\
\hline & & $\begin{array}{l}\text { Nonsevere } \\
\text { n (\%) }\end{array}$ & $\begin{array}{l}\text { Severe } \\
\text { n (\%) }\end{array}$ & $P$ Value ${ }^{a}$ \\
\hline \multicolumn{4}{|l|}{ Subtype } & .115 \\
\hline $\mathrm{HR}+/ \mathrm{HER} 2-$ & $5,956(76.0)$ & $3,831(76.7)$ & $2,125(74.7)$ & \\
\hline $\mathrm{HR} \pm / \mathrm{HER} 2+$ & $1,165(14.9)$ & $724(14.5)$ & $441(15.5)$ & \\
\hline HR-/HER2- & $717(9.1)$ & $438(8.8)$ & $279(9.8)$ & \\
\hline Missing & 64 & 36 & 28 & \\
\hline \multicolumn{4}{|l|}{ Breast cancer surgery } & .0094 \\
\hline Mastectomy & $2,085(26.4)$ & $1,278(25.4)$ & $807(28.1)$ & \\
\hline Partial mastectomy & $5,817(73.6)$ & $3,751(74.6)$ & $2,066(71.9)$ & \\
\hline Missing & - & - & - & \\
\hline \multicolumn{4}{|l|}{ Axillary surgery } & $<.0001$ \\
\hline Axillary dissection & $2,988(37.8)$ & $1,803(35.8)$ & $1,185(41.2)$ & \\
\hline Sentinel node & $4,914(62.2)$ & $3,226(64.1)$ & $1,688(58.7)$ & \\
\hline Missing & - & - & - & \\
\hline \multicolumn{4}{|l|}{ Chemotherapy } & $<.0001$ \\
\hline Yes & $3,749(47.4)$ & $2,488(49.5)$ & $1,664(57.9)$ & \\
\hline No & $4,152(52.5)$ & $2,540(50.5)$ & $1,209(42.1)$ & \\
\hline Missing & 1 & 1 & - & \\
\hline \multicolumn{4}{|l|}{ Radiation therapy } & .126 \\
\hline Yes & $7,253(91.9)$ & $4,597(91.5)$ & $2,656(92.5)$ & \\
\hline No & $643(8.1)$ & $427(8.5)$ & $216(7.5)$ & \\
\hline Missing & 6 & 5 & 1 & \\
\hline \multicolumn{4}{|l|}{ Endocrine therapy } & .783 \\
\hline Yes & $6,453(81.7)$ & $4,111(81.8)$ & $2,342(81.5)$ & \\
\hline No & $1,445(18.3)$ & $915(18.2)$ & $530(18.4)$ & \\
\hline Missing & 4 & 3 & 1 & \\
\hline \multicolumn{4}{|l|}{ Anti-HER2 therapy } & .045 \\
\hline Yes & $949(12.0)$ & $576(11.5)$ & $373(13.0)$ & \\
\hline No & $6,951(88.0)$ & $4,451(88.5)$ & $2,500(87.0)$ & \\
\hline Missing & 2 & 2 & - & \\
\hline \multicolumn{4}{|l|}{ Center volume $^{d}$} & .430 \\
\hline Small to medium $(<1,000)$ & $5,956(75.4)$ & $3,776(75.1)$ & $2,180(75.9)$ & \\
\hline Large $(\geq 1,000)$ & $1,946(24.6)$ & $1,253(24.9)$ & $693(24.1)$ & \\
\hline Missing & - & - & - & \\
\hline \multicolumn{4}{|l|}{ Pain (EORTC QLQ-C30) } & $<.0001$ \\
\hline Mean $[S D]$ score & $28.3[26.3]$ & $18.3[19.2]$ & $45.9[27.8]$ & \\
\hline Missing & 15 & 11 & 4 & \\
\hline \multicolumn{4}{|c|}{ Systemic therapy AEs (EORTC QLQ-C30) } & $<.0001$ \\
\hline Mean $[S D]$ score & $19.9[16.4]$ & 14.5 [12.3] & $29.5[18.4]$ & \\
\hline Missing & 65 & 37 & 28 & \\
\hline \multicolumn{4}{|c|}{ Arm symptoms (EORTC QLQ-B23) } & $<.0001$ \\
\hline Mean $[S D]$ score & $27.2[27.0]$ & $20.4[22.6]$ & $39.2[29.8]$ & \\
\hline Missing & 72 & 41 & 31 & \\
\hline
\end{tabular}




\section{Table 1. Cohort Characteristics of Participants With Posttreatment CRF Data (cont.)}

\begin{tabular}{|c|c|c|c|c|}
\hline \multirow[b]{2}{*}{ Characteristic } & \multirow[b]{2}{*}{$\begin{array}{l}\text { Whole Cohort } \\
\text { n (\%) }\end{array}$} & \multicolumn{3}{|c|}{ CRF } \\
\hline & & $\begin{array}{l}\text { Nonsevere } \\
\text { n (\%) }\end{array}$ & $\begin{array}{l}\text { Severe } \\
\text { n (\%) }\end{array}$ & $P$ Value $^{\text {a }}$ \\
\hline Arthralgia $^{b}$ & & & & $<.0001$ \\
\hline Any grade & $3,784(48.4)$ & $2,121(42.6)$ & $1,663(58.5)$ & \\
\hline No & $4,030(51.6)$ & $2,852(57.3)$ & $1,178(41.5)$ & \\
\hline Missing & 88 & 56 & 32 & \\
\hline Any grade & $2,082(26.6)$ & $1,084(21.8)$ & $998(35.1)$ & \\
\hline No & $5,732(73.4)$ & $3,889(78.2)$ & $1,843(64.9)$ & \\
\hline Missing & 88 & 56 & 32 & \\
\hline Neuropathy ${ }^{b}$ & & & & $<.0001$ \\
\hline Any grade & $349(4.5)$ & $179(3.6)$ & $170(6.0)$ & \\
\hline
\end{tabular}

Abbreviations: $A E$, adverse effect; $C R F$, cancer-related fatigue; HR, hormone receptor; MET, metabolic equivalent of task; PA, physical activity; Q1, quartile 1; Q3, quartile 3; EORTC QLQ-30, EORTC Core Quality of Life Questionnaire.

a Using chi-square tests and Wilcoxon rank-sum tests for categorical and continuous variables, as appropriate.

${ }^{b}$ Variables collected during the first posttreatment visit (after completion of primary treatment). Anxiety and depression were assessed using the validated

Hospital Anxiety and Depression Scale. ${ }^{68,69}$ All other variables were assessed at breast cancer diagnosis.

${ }^{\mathrm{c}}$ Breast cancer stage definition followed the AJCC 7th edition classification.

${ }^{d}$ Based on number of patients recruited in the CANTO study.

those who were insufficiently active (mean change [95\% $\mathrm{CI}],+0.30[+0.03$ to +0.51$]$ and $-0.07[-0.37$ to +0.22$] \mathrm{h} /$ $\mathrm{d}$, respectively; $P<.0001$ for interaction) (supplemental eTable 2).

There were 677 patients $(9.8 \%)$ who consulted with a psychologist, $479(6.9 \%)$ who consulted with a psychiatrist, 529 (7.7\%) who consulted with an acupuncturist, and $675(9.8 \%)$ who consulted with a CAM practitioner (Table 2). Compared with patients without severe global CRF, those with severe CRF had a slightly higher propensity to participate in a psychology $(13.8 \%$ vs $7.5 \%$; aOR, 1.29 ; $95 \%$ CI, $1.05-1.58 ; P=.014)$, psychiatry $(10.4 \%$ vs 5.0\%; aOR, 1.39; 95\% CI, 1.10-1.76; $P=.0064$ ), acupuncture consultation $(9.8 \%$ vs $6.5 \%$; aOR, $1.46 ; 95 \% \mathrm{CI}$, $1.17-1.82 ; P=.0008$ ), or CAM (12.5\% vs $8.2 \%$; aOR, 1.49 ; 95\% CI, 1.23-1.82; $P<.0001$ ) (Table 3).

Table 3 presents associations of uptake of PA recommendations and consultations with other healthcare providers with demographic, clinical, tumor, and treatmentrelated covariates. Notably, no significant interactions between severe CRF and anxiety or depressive symptoms related to the use of either psychologic or psychiatric services service emerged. Overall, as shown in supplemental eFigure 1, among those who qualified as non-cases of anxiety or depression, rates of use of mental healthcare services were consistently almost 2 -fold for severely versus nonseverely fatigued patients. For example, $12.8 \%$ versus $6.9 \%$ of them saw a psychologist and $7.3 \%$ versus $4.7 \%$ saw a psychiatrist and were non-cases of depression, respectively.
However, service use rates were generally higher among patients with at least doubtful symptoms, reflecting model results. In addition, psychologic consultations were more frequent among patients without severe CRF when overt symptoms of depression were present $(16.9 \%$ vs $20.2 \%$ for patients with severe and nonsevere CRF, respectively).

\section{CRF Dimensions and Recommendation Uptake}

Severe physical CRF was associated with reduced engagement in PA (aOR, 0.74; 95\% CI, 0.63-0.86; $P=.0001$ ), whereas severe emotional CRF with increased odds of psychologic consultations (aOR, 1.37; 95\% CI, 1.06-1.79; $P=.017$ ) and severe cognitive $\mathrm{CRF}$ with increased psychiatric (aOR, 1.56; 95\% CI, 1.16-2.11; $P=.0037$ ) and acupuncture consultations (aOR, 1.49; 95\% CI, 1.10-2.04; $P=.011)$. No specific patterns emerged for CAM consultations (Table 4).

\section{Sensitivity Analyses}

Analyses incorporating PROs and CTCAE toxicities showed some additional relevant associations, including between pain, systemic therapy adverse effects, and acupuncture use (supplemental eTable 3). Consistent results with main analyses were found modeling CRF as continuous (supplemental eTable 4) and in models including endocrine and anti-HER2 therapy as covariates (data not shown). 


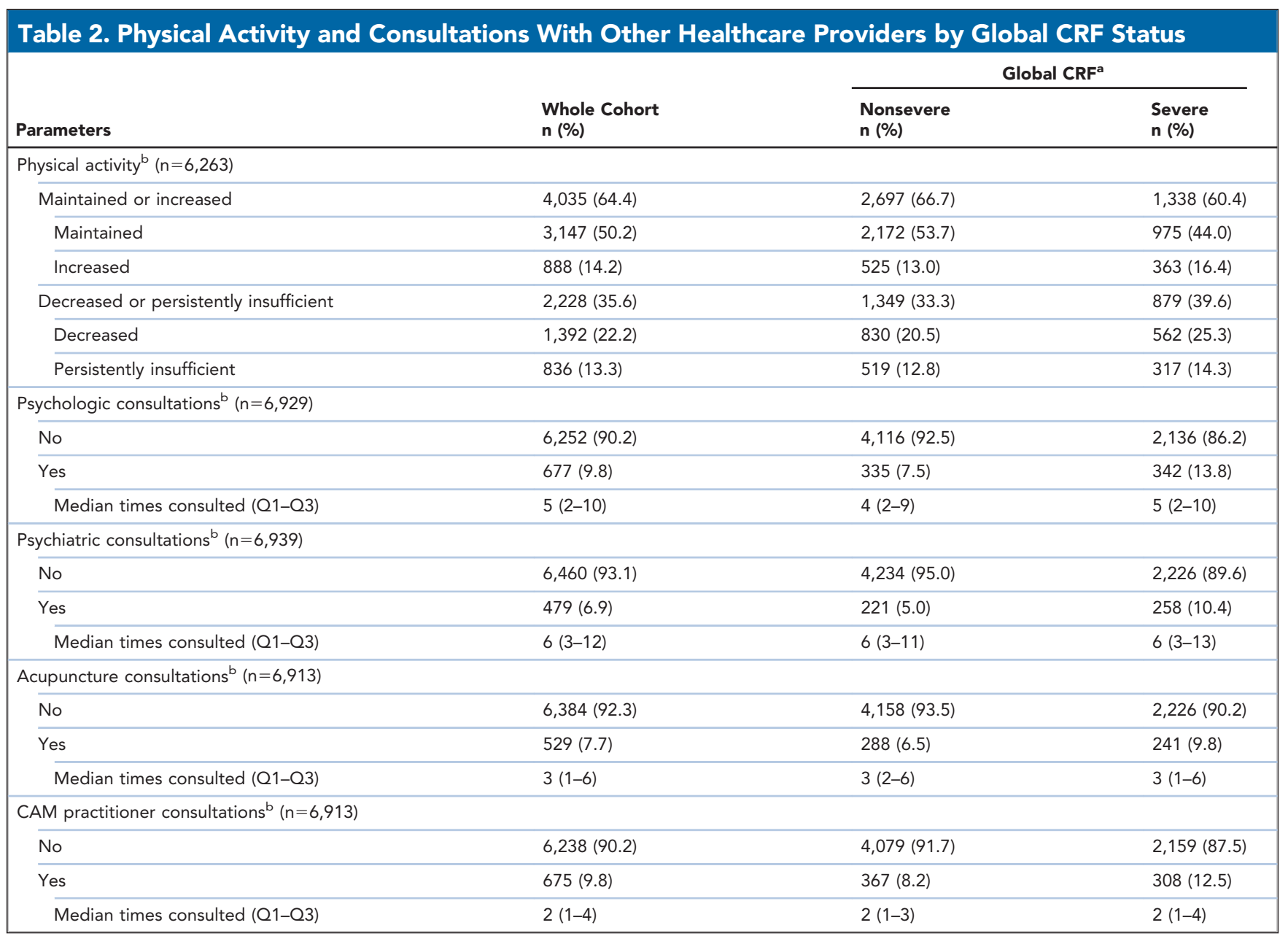

Abbreviations: CAM, complementary and alternative medicine; CRF, cancer-related fatigue; Q1, quartile 1; Q3, quartile 3.

${ }^{a} \mathrm{G}$ lobal CRF status was assessed during the first posttreatment visit.

${ }^{b}$ Physical activity and participation in consultations with other healthcare providers were assessed over the course of the year after the CRF assessment.

\section{Discussion}

We evaluated the association between posttreatment CRF and uptake of specific CRF management strategies in the year after treatment completion among patients with early-stage BC. Reporting severe global CRF was associated with reduced uptake of recommended PA levels and with a slightly higher likelihood of consultations with other healthcare practitioners during the year after CRF evaluation. Among patients with severe CRF, $40 \%$ did not adhere to PA recommendations, whereas only approximately $14 \%$ and $10 \%$ consulted with psychologists and psychiatrists, respectively, and $10 \%$ consulted with acupuncturists, similar to a nearly $13 \%$ who saw a CAM practitioner offering homeopathy and/or naturopathy strategies. There were differential associations across physical, emotional, and cognitive dimensions of CRF.

Recommendations for CRF exist for survivors in the posttreatment setting, including dedicated NCCN and ASCO practice guidelines. ${ }^{26,33}$ Our study highlights a need to optimize the implementation of available options.

Rest and limitation of physically demanding tasks are often mistakenly reported by patients and providers as strategies to relieve $\mathrm{CRF}^{27}$ In fact, cancer survivors with CRF should be encouraged to avoid physical inactivity and to engage in any PA type, pace, and intensity to meet exercise recommendations. ${ }^{26,50}$ However, significant increments in sedentary behavior, which includes time spent sitting or reclining while at work, at home, or traveling, were present among patients who initially qualified as sufficiently active and who also reported severe CRF. Compared with patients without severe CRF, fewer of these patients maintained their initial levels of PA. Severe CRF seemed therefore to represent a major barrier to exercise in our cohort, particularly its physical dimension, which is known to have the highest correlation with global $\mathrm{CRF}^{26}$ Other factors were previously cited as barriers for patients with cancer that prevent them from engaging in PA, including therapy-related symptoms, higher 


\begin{tabular}{|c|c|c|c|c|c|}
\hline \multirow[b]{2}{*}{ Parameters } & \multirow{2}{*}{$\begin{array}{l}\text { Maintained or Increased } \\
\text { Physical Activity } \\
\text { aOR }(95 \% \mathrm{Cl})\end{array}$} & \multicolumn{4}{|c|}{ Other HCPs } \\
\hline & & $\begin{array}{l}\text { Psychologist } \\
\text { aOR }(95 \% \mathrm{Cl})\end{array}$ & $\begin{array}{l}\text { Psychiatrist } \\
\text { aOR }(95 \% \mathrm{Cl})\end{array}$ & $\begin{array}{l}\text { Acupuncturist } \\
\text { aOR }(95 \% \mathrm{Cl})\end{array}$ & $\begin{array}{l}\text { CAM Practitioner } \\
\text { aOR }(95 \% \mathrm{Cl})\end{array}$ \\
\hline Event rate, n/N (\%) & $4,035 / 6,263(64.4 \%)$ & $677 / 6,929(9.8 \%)$ & $479 / 6,939(6.9 \%)$ & $529 / 6,913(7.6 \%)$ & $675 / 6,913(9.8 \%)$ \\
\hline \multicolumn{6}{|l|}{ Global CRF status $^{a}$} \\
\hline Nonsevere & Ref & Ref & Ref & Ref & Ref \\
\hline Severe & $0.82(0.71-0.94)$ & $1.29(1.05-1.58)$ & $1.39(1.10-1.76)$ & $1.46(1.17-1.82)$ & $1.49(1.23-1.82)$ \\
\hline \multicolumn{6}{|l|}{ Age at diagnosis } \\
\hline Continuous, $1-y$ increment & $0.99(0.99-1.00)$ & $0.97(0.96-0.98)$ & $0.98(0.97-0.99)$ & $0.99(0.98-1.00)$ & $1.00(0.99-1.01)$ \\
\hline \multicolumn{6}{|l|}{ Body mass index ${ }^{a}$} \\
\hline Continuous, 1 -unit increment & $0.95(0.94-0.96)$ & $0.99(0.98-1.01)$ & $0.99(0.97-1.01)$ & $0.99(0.97-1.01)$ & $0.98(0.97-1.00)$ \\
\hline \multicolumn{6}{|l|}{ Charlson comorbidity index score } \\
\hline 0 & Ref & Ref & Ref & Ref & Ref \\
\hline$\geq 1$ & $1.01(0.86-1.18)$ & $0.99(0.79-1.28)$ & $0.89(0.66-1.20)$ & $0.95(0.73-1.25)$ & $0.90(0.71-1.15)$ \\
\hline \multicolumn{6}{|l|}{ Anxiety ${ }^{a}$} \\
\hline Non-case & Ref & Ref & Ref & Ref & Ref \\
\hline Doubtful & $1.07(0.92-1.24)$ & $2.26(1.79-2.85)$ & $1.33(1.01-1.76)$ & $1.20(0.93-1.54)$ & $1.18(0.94-1.47)$ \\
\hline Case & $1.28(1.07-1.53)$ & $2.79(2.17-3.59)$ & $2.04(1.53-2.71)$ & $1.61(1.23-2.22)$ & $1.09(0.85-1.42)$ \\
\hline \multicolumn{6}{|l|}{ Depression $^{a}$} \\
\hline Non-case & Ref & Ref & Ref & Ref & Ref \\
\hline Doubtful & $0.83(0.67-1.01)$ & $1.22(0.92-1.60)$ & $1.79(1.31-2.44)$ & $0.74(0.53-1.04)$ & $1.06(0.79-1.41)$ \\
\hline Case & $0.63(0.48-0.83)$ & $1.51(1.08-2.13)$ & $2.96(2.07-4.22)$ & $0.75(0.48-1.17)$ & $1.04(0.71-1.54)$ \\
\hline \multicolumn{6}{|l|}{ Highest education level } \\
\hline College degree or higher & Ref & Ref & Ref & Ref & Ref \\
\hline High school & $0.71(0.62-0.83)$ & $0.70(0.57-0.87)$ & $0.46(0.36-0.58)$ & $0.61(0.49-0.77)$ & $0.65(0.54-0.80)$ \\
\hline Primary school & $0.56(0.45-0.69)$ & $0.36(0.23-0.57)$ & $0.22(0.13-0.40)$ & $0.45(0.29-0.69)$ & $0.27(0.17-0.41)$ \\
\hline
\end{tabular}

BMI, more severe depression, and financial difficulties. ${ }^{27}$ In this study, we could also investigate the contribution of such factors to adherence with PA recommendations, which was, as expected, lower among women with higher BMI and worse depression. In contrast, symptoms such as pain and other treatment-related sequelae seemed to play only a marginal role compared with CRF, which remained significantly associated with reduced uptake of PA recommendations after accounting for all these relevant clinical and contextual factors.

Indications exist to refer cancer survivors for psychosocial interventions to address $\mathrm{CRF}^{26}$ Cognitive behavioral therapy, by targeting dysfunctional thoughts, poor coping strategies, and alterations in sleep patterns, and psychoeducational therapies that offer information about CRF and that correct maladaptive thoughts such as overdramatizing, are capable of improving CRF significantly. ${ }^{51,52}$ In the CANTO study, the use of consultations with psychologists and psychiatrists seemed to be appropriately impacted by the presence of severe CRF. However, this observation should be discussed in the context of the strong interplay between CRF and symptoms of psychologic distress, ${ }^{12}$ because the use of mental health services is indicated for such symptoms in both the presence and absence of CRF. Severe CRF is indeed rarely isolated and often occurs as part of the somatic expression of more complex mental conditions, clustering with physical and emotional symptoms of depression and anxiety. ${ }^{26,53,54}$ Particularly, CRF can represent a symptom of depression, but it might also determine precipitation of a depressed mood by interference with regular functioning and activities. ${ }^{12}$ In our models, we tried to isolate the contribution of CRF and psychologic distress as drivers of use of psychologic and psychiatric services, showing an independent association with CRF, regardless of adjustment for anxiety and depression levels, with nonsignificant interaction terms. We acknowledge that statistical controls may not be able to fully disentangle this relationship. Use of mental healthcare services was substantially more common if patients reported at least doubtful symptoms of emotional distress, 


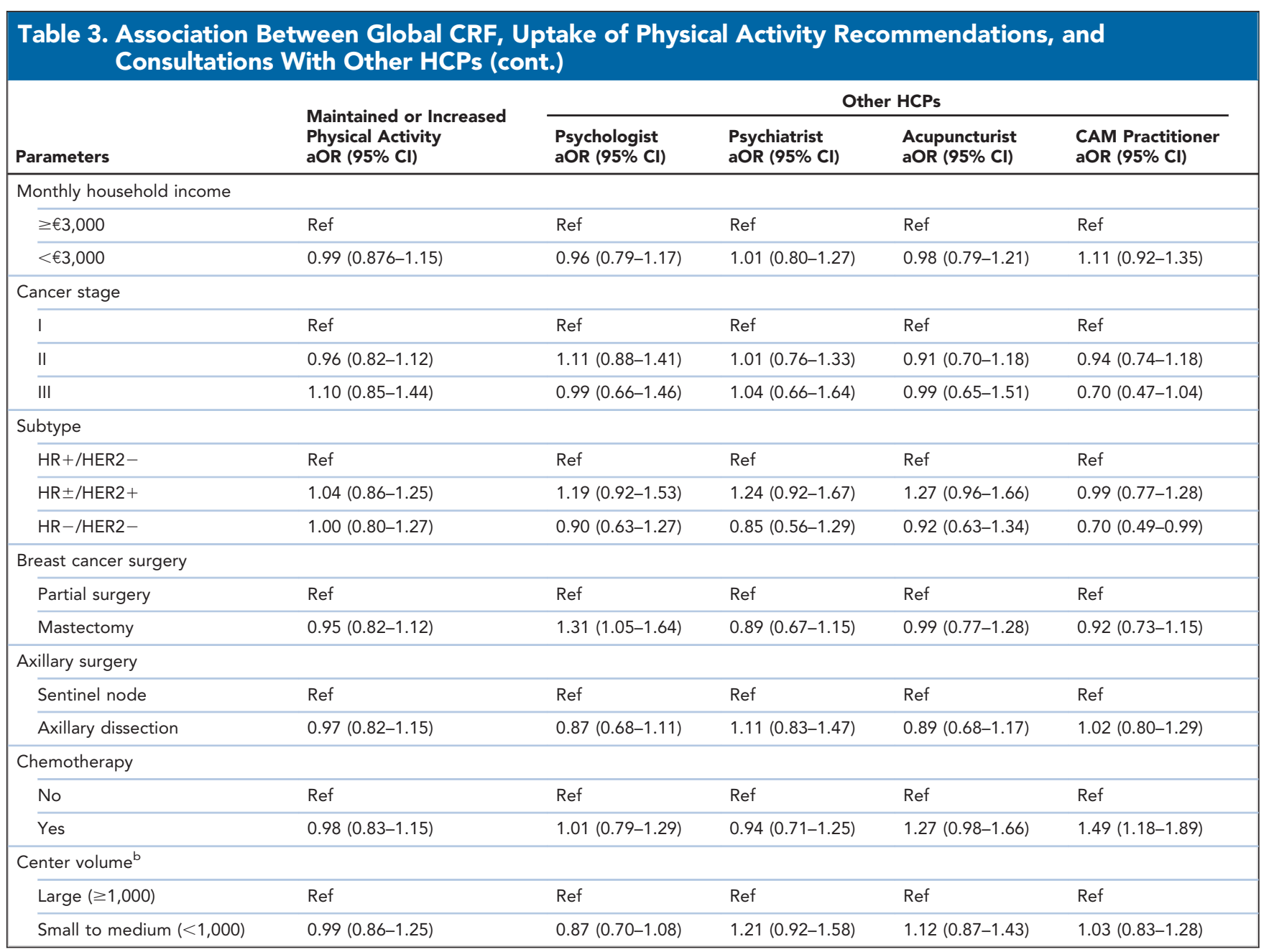

Data were adjusted for all factors in the table.

Abbreviations: aOR, adjusted odds ratio; CAM, complementary and alternative medicine; CRF, cancer-related fatigue; HCP, healthcare provider; HR, hormone receptor.

a Variables collected during the first posttreatment visit (after completion of primary treatment). All other variables were assessed at breast cancer diagnosis. Physical activity and participation in consultations with other HCPs were assessed over the course of the year after the CRF assessment.

${ }^{d}$ Based on number of patients recruited in the CANTO study.

and psychologic support was more frequently used in the absence of severe CRF by patients qualifying as having clinically diagnosed depression. Furthermore, strategies adopted for CRF in our study were strongly correlated with specific symptom dimensions, with psychologic consultations being more commonly used by women with severe emotional CRF complaints (ie, frequently reporting "feelings of helplessness" or "frustration" [EORTC QLQ-FA12]). We may therefore assume that what we are observing is also part of the pattern of referral to mental health services among women with a history of BC who experience actual mood disorders, struggling with clinically meaningful symptoms of psychologic distress in addition to severe CRF.

Nevertheless, our data also speak to the fact that only a minority of women were reported to have seen a mental healthcare provider $(9.8 \%$ and $6.9 \%$ saw a psychologist or psychiatrist, respectively), similar to the $10 \%$ rate reported among the general French population with psychologic distress. ${ }^{55,56}$ Although CANTO is an observational clinical study describing a routinely treated clinical population in which no specific efforts are made to educate patients on how to manage CRF, these data can generate several considerations. We may propose different explanations for the observed low rates of service use. First, patients and providers may be unaware of the rationale and efficacy of using psychosocial approaches to treat CRF because there is often limited attention to $\mathrm{CRF}$ correlates falling outside of strictly physical attributes and insufficient understanding of the applicability of approaches such as cognitive behavioral therapy outside of the context of mental or mood disorders. ${ }^{57-60}$ Second, socioenvironmental pressure persists, building on negative stereotypes and prejudicial beliefs toward mental health 


\begin{tabular}{|c|c|c|c|c|c|}
\hline Parameters & $\begin{array}{l}\text { Maintained or Increased } \\
\text { Physical Activity } \\
\text { aOR }(95 \% \mathrm{Cl})\end{array}$ & \multicolumn{4}{|c|}{ Other HCPs } \\
\hline Event rate, $\mathrm{n} / \mathrm{N}(\%)$ & $4,035 / 6,263(64.4 \%)$ & $677 / 6,929$ (9.8\%) & $479 / 6,939(6.9 \%)$ & $529 / 6,913(7.6 \%)$ & $675 / 6,913(9.8 \%)$ \\
\hline Severe & $0.74(0.63-0.86)$ & $1.26(1.01-1.60)$ & $1.33(1.01-1.75)$ & $1.12(0.86-1.44)$ & $1.20(0.95-1.50)$ \\
\hline \multicolumn{6}{|c|}{ Emotional CRF status ${ }^{\mathrm{a}}$} \\
\hline Nonsevere & Ref & Ref & Ref & Ref & Ref \\
\hline Severe & $0.98(0.80-1.19)$ & $1.37(1.06-1.79)$ & $1.02(0.75-1.39)$ & $1.11(0.82-1.51)$ & $1.09(0.83-1.44)$ \\
\hline
\end{tabular}

Models were adjusted for age, body mass index, comorbidities, anxiety and depression, education, income, tumor stage and subtype, breast cancer and axillary surgery, receipt of chemotherapy, and center volume.

Abbreviations: aOR, adjusted odds ratio; CAM, complementary and alternative medicine; CRF, cancer-related fatigue; HCP, healthcare provider.

${ }^{a}$ Variables collected during the first posttreatment visit (after completion of primary treatment). Physical activity and participation in consultations with other HCPs were assessed over the course of the year after the CRF assessment.

services. ${ }^{61}$ Patients could be hesitant to seek psychosocial support or may be inclined to underreport use. For similar reasons, the referral may occur quite late, when patients are already experiencing severe CRF or overt emotional distress symptoms, and not up front, during the organization of the posttreatment survivorship care plan. This may urge a paradigm shift. When needed, patients with BC should be promptly referred to psycho-oncologic services, and psychotherapists should be included in the multidisciplinary discussions as early as possible. The involvement of general mental healthcare from services in the community should also be considered. Stigmatization may also exert a differential impact on attitudes toward access to psychologic versus psychiatric services. Caregivers, patients, and their families seem to tend to first approach less-stigmatizing health professionals, such as psychologists (but also neurologists and general practitioners), further delaying help-seeking, and resourcing poorly particularly to psychiatrists. ${ }^{61-63}$ Education on the availability of mental health services to manage CRF should target both providers and patients, ${ }^{33,61}$ in effort to reduce the stigmatization associated with prevention and management of mental conditions and psychologic distress that can consequently translate into severe CRF symptoms. Third, to increase use rates of psychosocial services among patients with CRF, more work is also needed to move toward the establishment of an improved (and less paternalistic) patient-physician partnership model. This model should promote a more active involvement of patients along the care pathway, supporting a systematic assessment of CRF and other patient-reported symptoms and using tools to monitor psychoemotional status and availability of coping resources, eventually serving as a shared decision aid to trigger timely and effective participation of patients in consultations with mental health specialists. ${ }^{64,65}$ Finally, psychologic therapy comes with nonreimbursed out-of-pocket costs for patients during posttreatment follow-up in France, representing an additional relevant barrier.

Acupuncture can also be helpful for patients with $\mathrm{CRF}^{26,33}$ Nevertheless, only one-tenth of severely fatigued survivors reported participation in posttreatment acupuncture sessions, with pain and other systemic therapy-related effects (particularly related to receipt chemotherapy, as captured by the EORTC QLQ-BR23) also emerging as significant associations with its use. In contrast, we observed very consistent associations linking severe $\mathrm{CRF}$ with subsequent consultations with CAM practitioners offering homeopathy and/or naturopathy, similar to findings of other CANTO analyses from our group. ${ }^{66}$ Patients in the CANTO study reported an interest in strategies for which we have robust evidence, such as psychotherapy, at roughly the same rates as they did for these CAM approaches that lack solid efficacy data and therefore should not be recommended for CRF in the posttreatment setting. ${ }^{41}$

Some study limitations should be acknowledged, including risk of misreporting, recall bias, and residual Hawthorne effect, because the "awareness of being observed" could affect reported or actual PA among individuals who are cognizant to be on study. Nevertheless, as previously observed, this effect is minimized by the longterm observation and data collection. ${ }^{67}$ Furthermore, use of specific mind-body strategies, including yoga and 
mindfulness approaches, was not granularly documented in CANTO. We also acknowledge that CAM therapies encompass a broad range of practices ${ }^{41}$ not limited to homeopathy and naturopathy, which we grouped under this definition upon data availability in CANTO. The reason for consultation of healthcare providers and information about decision-making actors of referral plans was not collected in this observational study. Sensitivity analyses correcting for healthcare settings could not be performed (eg, academic vs general hospital), because center of care is not identifiable by law. However, we assessed the volume of patients enrolled by center to address this limitation. Patients were mainly included from reference facilities in centralized cancer care systems and urban areas; therefore, this analysis may mirror practice at larger centers. Nevertheless, this further stresses the need for better CRF care plans, which currently do not seem to be optimally implemented even at facilities exclusively focused on cancer care. Referral patterns and uptake of recommendations may be impacted by the availability of PA programs and mental health services and by access- and cost-related issues within different healthcare systems outside of France. However, our results should be generalizable to other countries with equivalent systems.

CANTO has a number of strengths that we want to highlight. It represents an unparalleled effort in the modern survivorship research arena, and is one of the largest longitudinal studies of women with early BC worldwide addressing complex and multifaceted issues. ${ }^{42}$ Specific to the present analysis, a wealth of medical, patient-reported, $\mathrm{CRF}$, and healthcare strategy data made CANTO a unique dataset to explore CRF-related questions. CRF was extensively evaluated using a unidimensional scale (QLQ-C30, which is brief and easy to use, mostly capturing the physical impact of CRF), complemented with a multidimensional scale (QLQ-FA12) incorporating emotional and cognitive impacts. Completion rates were high at time points of interest. Finally, several sensitivity analyses confirmed the robustness of our findings.

\section{Conclusions}

CANTO data show that, among many posttreatment BC survivors complaining of severe CRF (nearly 1 in 3), strategies that could help improve their condition, such as adhering to exercise guidelines or use of psychosocial services, risk being largely underused or not optimally implemented. Concomitantly, there seems to be a nonnegligible interest in non-evidence-based CAM approaches, such as homeopathy and naturopathy. Personalized survivorship care plans can help optimize the use of strategies to improve a highly prevalent condition such as CRF while patients transition from their primary care into long-term follow-up. Better coordination of care among oncologists, exercise specialists, and other supportive care providers, as part of an integrated CRF management team that also involves community-based services, is needed to improve patient education and provide adequate guidance to alleviate CRF, a complex syndrome with substantial downstream impact.

Submitted August 20, 2020; final revision received November 5, 2020; accepted for publication April 26, 2021. Published online February 7, 2022.

Previous presentation: Results of this study were partly presented the ESMO Breast Cancer Virtual Meeting; May 23-24, 2020. Proffered Paper session 1. Ann Oncol 2020;31(Suppl 2):S83-87.

Author contributions: Study concept: Di Meglio, Charles, E. Martin, Flaysakier, A.L. Martin, Everhard, Laas, Chopin, Vanlemmens, Jouannaud, Levy, Rigal, Fournier, Soulie, Scotte, Pistilli, Dumas, Menvielle, André, Michiels, Dauchy, Vaz-Luis. Data curation: Di Meglio, Havas, Gbenou, Vaz-Luis. Formal analysis: Di Meglio, Havas, Gbenou, Vaz-Luis. Funding acquisition: Di Meglio, Vaz-Luis. Investigation: Di Meglio, Charles, E. Martin Flaysakier, A.L. Martin, Everhard, Laas, Chopin, Vanlemmens, Jouannaud, Levy, Rigal, Fournier, Soulie, Scotte, Pistilli, Dumas, Menvielle, André, Michiels, Dauchy, Vaz-Luis. Methodology: All authors. Project administration: Di Meglio, A.L. Martin, Everhard, Vaz-Luis. Resources: Di Meglio, A.L. Martin, Everhard, Vaz-Luis. Software: Di Meglio, Vaz-Luis. Supervision: Di Meglio, Vaz-Luis. Validation: Di Meglio, Charles, E. Martin, Flaysakier, A.L. Martin, Everhard, Laas, Chopin, Vanlemmens, Jouannaud, Levy, Rigal, Fournier, Soulie, Scotte, Pistilli, Dumas, Menvielle, André, Michiels, Dauchy, Vaz-Luis. Visualization: Di Meglio, Vaz-Luis. Writing - original draft: Di Meglio, Vaz-Luis. Writing - review and editing: Di Meglio, Vaz-Luis.

Disclosures: Dr. Michiels has disclosed serving on a data safety monitoring board for Sensorion, Biophytis, Servier, and Yuhan, and serving as a consultant for IDDI, Amaris, and Roche. Dr. Vaz-Luis has disclosed receiving honoraria for education purposes (institutional) from AstraZeneca and Pfizer/Edimark. The remaining authors have disclosed that they have not received any financial consideration from any person or organization to support the preparation, analysis, results, or discussion of this article.

Funding: This work was supported by funding from a Career Pathway Grant in Symptom Management from Conquer Cancer, ASCO, and Rising Tide Foundation for Clinical Cancer Research (A. Di Meglio), Susan G. Komen (CCR17483507 to I. Vaz-Luis), Odyssea (I. Vaz-Luis), the French Foundation for Cancer Research (I. Vaz-Luis), Fondation Gustave Roussy (I. Vaz-Luis), and Breast Cancer Research Foundation. The CANTO study is supported by the French Government under the "Investment for the Future" program, managed by the National Research Agency (ANR), grant N. ANR-10-COHO-0004.

Correspondence: Ines Vaz-Luis, MD, PhD, Institut Gustave Roussy, 114 Rue Edouard Vaillant, 94800 Villejuif, France.

Email: ines-maria.vaz-duarte-luis@gustaveroussy.fr

\section{References}

1. Bray F, Ferlay J, Soerjomataram I, et al. Global cancer statistics 2018 : GLOBOCAN estimates of incidence and mortality worldwide for 36 cancers in 185 countries. CA Cancer J Clin 2018;68:394-424.

2. Siegel RL, Miller KD, Jemal A. Cancer statistics, 2019. CA Cancer J Clin 2019;69:7-34
3. Coleman MP, Quaresma M, Berrino F, et al. Cancer survival in five continents: a worldwide population-based study (CONCORD). Lancet Oncol 2008;9:730-756.

4. Stan D, Loprinzi CL, Ruddy KJ. Breast cancer survivorship issues. Hematol Oncol Clin North Am 2013;27:805-827, ix. 
5. Hofman M, Ryan JL, Figueroa-Moseley CD, et al. Cancer-related fatigue: the scale of the problem. Oncologist 2007;12(Suppl 1): 4-10.

6. Bower JE, Ganz PA, Desmond KA, et al. Fatigue in long-term breast carcinoma survivors: a longitudinal investigation. Cancer 2006;106: 751-758.

7. Bower JE, Ganz PA, Desmond KA, et al. Fatigue in breast cancer survivors: occurrence, correlates, and impact on quality of life. J Clin Oncol 2000:18:743-753.

8. Abrahams HJG, Gielissen MFM, Schmits IC, et al. Risk factors, prevalence, and course of severe fatigue after breast cancer treatment: a meta-analysis involving 12327 breast cancer survivors. Ann Oncol 2016; 27:965-974.

9. Poulson MJ. Not just tired. J Clin Oncol 2001;19:4180-4181.

10. Andrykowski MA, Donovan KA, Laronga C, et al. Prevalence, predictors, and characteristics of off-treatment fatigue in breast cancer survivors. Cancer 2010;116:5740-5748.

11. Cella D, Lai JS, Chang $\mathrm{CH}$, et al. Fatigue in cancer patients compared with fatigue in the general United States population. Cancer 2002;94: 528-538.

12. Bower JE. Cancer-related fatigue-mechanisms, risk factors, and treatments. Nat Rev Clin Oncol 2014;11:597-609.

13. Cella D, Davis K, Breitbart W, et al. Cancer-related fatigue: prevalence of proposed diagnostic criteria in a United States sample of cancer survivors. J Clin Oncol 2001;19:3385-3391.

14. Minton $O$, Stone P. A systematic review of the scales used for the measurement of cancer-related fatigue (CRF). Ann Oncol 2009;20:17-25.

15. Curt GA, Breitbart W, Cella D, et al. Impact of cancer-related fatigue on the lives of patients: new findings from the Fatigue Coalition. Oncologist 2000;5:353-360

16. Broeckel JA, Jacobsen PB, Horton J, et al. Characteristics and correlates of fatigue after adjuvant chemotherapy for breast cancer. J Clin Oncol 1998;16:1689-1696.

17. Collado-Hidalgo A, Bower JE, Ganz PA, et al. Inflammatory biomarkers for persistent fatigue in breast cancer survivors. Clin Cancer Res 2006;12 2759-2766.

18. Bower JE, Ganz PA, Irwin MR, et al. Fatigue and gene expression in human leukocytes: increased NF- $\kappa \mathrm{B}$ and decreased glucocorticoid signaling in breast cancer survivors with persistent fatigue. Brain Behav Immun 2011;25:147-150.

19. Orre IJ, Reinertsen KV, Aukrust P, et al. Higher levels of fatigue are associated with higher CRP levels in disease-free breast cancer survivors. J Psychosom Res 2011;71:136-141.

20. Bower JE, Ganz PA, Tao ML, et al. Inflammatory biomarkers and fatigue during radiation therapy for breast and prostate cancer. Clin Cancer Res 2009; 15:5534-5540.

21. Geinitz H, Zimmermann FB, Stoll $P$, et al. Fatigue, serum cytokine levels and blood cell counts during radiotherapy of patients with breast cancer. Int J Radiat Oncol Biol Phys 2001;51:691-698.

22. Cramp F, Byron-Daniel J. Exercise for the management of cancer-related fatigue in adults. Cochrane Database Syst Rev 2012;11:CD006145.

23. Patel AV, Friedenreich CM, Moore SC, et al. American College of Sports Medicine Roundtable Report on Physical Activity, Sedentary Behavior, and Cancer Prevention and Control. Med Sci Sports Exerc 2019;51: 2391-2402.

24. Brown JC, Huedo-Medina TB, Pescatello LS, et al. Efficacy of exercise interventions in modulating cancer-related fatigue among adult cancer survivors: a meta-analysis. Cancer Epidemiol Biomarkers Prev 2011;20: 123-133.

25. Speck RM, Courneya KS, Mâsse LC, et al. An update of controlled physical activity trials in cancer survivors: a systematic review and meta-analysis. J Cancer Surviv 2010;4:87-100.

26. Bower JE, Bak K, Berger A, et al. Screening, assessment, and management of fatigue in adult survivors of cancer: an American Society of Clinical Oncology clinical practice guideline adaptation. J Clin Oncol 2014; 32:1840-1850

27. Bouillet $T$, Bigard X, Brami $C$, et al. Role of physical activity and sport in oncology: scientific commission of the National Federation Sport and Cancer CAMI. Crit Rev Oncol Hematol 2015;94:74-86.

28. Sebri V, Savioni L, Triberti S, et al. How to train your health: sports as a resource to improve cognitive abilities in cancer patients. Front Psychol 2019;10:2096.

29. Pierce S, Gould D, Camiré M. Definition and model of life skills transfer. Int Rev Sport Exerc Psychol 2017;10:186-211.
30. Sebri V, Savioni L, Triberti S, et al. Do you transfer your skills? From sports to health management in cancer patients. Front Psychol 2020; 11:546.

31. Duijts SFA, Faber MM, Oldenburg HSA, et al. Effectiveness of behavioral techniques and physical exercise on psychosocial functioning and healthrelated quality of life in breast cancer patients and survivors-a metaanalysis. Psychooncology 2011;20:115-126

32. Mind and body practices. National Center for Complementary and Integrative Health website. Accessed August 2, 2021. Available at: https:// www.nccih.nih.gov/health/mind-and-body-practices

33. Berger AM, Mooney K, Banerjee C, et al. NCCN Clinical Practice Guidelines in Oncology: Cancer-Related Fatigue. Version 1.2021. Accessed December 12, 2020. To view the most recent version, visit NCCN.org

34. Greenlee H, DuPont-Reyes MJ, Balneaves LG, et al. Clinical practice guidelines on the evidence-based use of integrative therapies during and after breast cancer treatment. CA Cancer J Clin 2017;67:194-232.

35. Towler P, Molassiotis A, Brearley SG. What is the evidence for the use of acupuncture as an intervention for symptom management in cancer supportive and palliative care: an integrative overview of reviews. Support Care Cancer 2013;21:2913-2923.

36. Posadzki P, Moon TW, Choi TY, et al. Acupuncture for cancer-related fatigue: a systematic review of randomized clinical trials. Support Care Cancer 2013;21:2067-2073.

37. Lau CHY, Wu X, Chung VCH, et al. Acupuncture and related therapies for symptom management in palliative cancer care: systematic review and meta-analysis. Medicine (Baltimore) 2016;95:e2901.

38. Vickers AJ, Straus DJ, Fearon B, et al. Acupuncture for postchemotherapy fatigue: a phase II study. J Clin Oncol 2004;22:1731-1735.

39. Molassiotis A, Sylt $P$, Diggins $H$. The management of cancer-related fatigue after chemotherapy with acupuncture and acupressure: a randomised controlled trial. Complement Ther Med 2007;15:228-237.

40. Lyman $\mathrm{GH}$, Bohlke K, Cohen L. Integrative therapies during and after breast cancer treatment: ASCO endorsement of the SIO clinical practice guideline summary. J Oncol Pract 2018;14:495-499.

41. Lyman GH, Greenlee H, Bohlke K, et al. Integrative therapies during and after breast cancer treatment: ASCO endorsement of the SIO clinical practice guideline. J Clin Oncol 2018;36:2647-2655.

42. Vaz-Luis I, Cottu P, Mesleard C, et al. UNICANCER: French prospective cohort study of treatment-related chronic toxicity in women with localised breast cancer (CANTO). ESMO Open 2019;4:e000562.

43. World Health Organization. Global Physical Activity Questionnaire Analy sis Guide. Accessed August 2, 2021. Available at: https://www.who.int/ ncds/surveillance/steps/resources/GPAQ_Analysis_Guide.pdf

44. Aaronson NK, Ahmedzai S, Bergman B, et al. The European Organization for Research and Treatment of Cancer QLQ-C30: a quality-of-life instrument for use in international clinical trials in oncology. J Natl Cancer Inst 1993:85:365-376.

45. Weis J, Tomaszewski KA, Hammerlid E, et al. International psychometric validation of an EORTC quality of life module measuring cancer related fatigue (EORTC QLQ-FA12). J Natl Cancer Inst 2017;109:djw273.

46. Sprangers MA, Groenvold M, Arraras JI, et al. The European Organization for Research and Treatment of Cancer breast cancer-specific qualityof-life questionnaire module: first results from a three-country field study. J Clin Oncol 1996;14:2756-2768.

47. Fayers $\mathrm{P}$, Aaronson NK, Bjordal K, et al. EORTC QLQ-C30 Scoring Manual. Brussels, Belgium: European Organisation for Research and Treatment of Cancer; 2001

48. Questionnaires. EORTC Quality of Life website. Accessed March 3, 2020 Available at: https://qol.eortc.org/questionnaires/

49. Giesinger JM, Loth FLC, Aaronson NK, et al. Thresholds for clinical importance were established to improve interpretation of the EORTC QLQ-C30 in clinical practice and research. J Clin Epidemiol 2020;118:1-8.

50. Puetz TW, Herring MP. Differential effects of exercise on cancer-related fatigue during and following treatment: a meta-analysis. Am J Prev Med 2012;43:e1-24.

51. Gielissen MFM, Verhagen CAHHVM, Bleijenberg G. Cognitive behaviou therapy for fatigued cancer survivors: long-term follow-up. Br J Cancer 2007:97:612-618.

52. Yun YH, Lee KS, Kim YW, et al. Web-based tailored education program for disease-free cancer survivors with cancer-related fatigue: a randomized controlled trial. J Clin Oncol 2012;30:1296-1303.

53. Brown LF, Kroenke K. Cancer-related fatigue and its associations with depression and anxiety: a systematic review. Psychosomatics 2009;50: 440-447 
54. Kim Y, Hickok JT, Morrow G. Fatigue and depression in cancer patients undergoing chemotherapy: an emotion approach. J Pain Symptom Manage 2006;32:311-321.

55. Saïas $T$, du Roscoät E, Véron L, et al. Psychological distress in French college students: demographic, economic and social stressors: results from the 2010 National Health Barometer. BMC Public Health 2014;14:256.

56. Husky MM, Guignard R, Beck F, et al. Risk behaviors, suicidal ideation and suicide attempts in a nationally representative French sample. J Affect Disord 2013;151:1059-1065.

57. Leichsenring F, Steinert C. Is cognitive behavioral therapy the gold standard for psychotherapy? The need for plurality in treatment and research. JAMA 2017;318:1323-1324.

58. Tirintica AR, Andjelkovic I, Sota $\mathrm{O}$, et al. Factors that influence access to mental health services in South-Eastern Europe. Int J Ment Health Syst 2018;12:75.

59. Charles C, Di Meglio I, A Arnedos, et al. QualFatigue study: which factors influence the use of specific interventions for breast cancer survivors with fatigue? A cross-sectional exploratory study. Support Care Cancer $2021 ; 29: 4827-4834$

60. Martin E, Zingarello A, Di Meglio A, et al. A qualitative evaluation of the use of interventions to treat fatigue among cancer survivors: a healthcare provider's view. Eur J Cancer Care (Engl) 2021;30:e13370.

61. Bhugra D, Sartorius N, Fiorillo A, et al. EPA guidance on how to improve the image of psychiatry and of the psychiatrist. Eur Psychiatry 2015;30: 423-430.
62. Gaebel W, Zäske H, Zielasek J, et al. Stigmatization of psychiatrists and general practitioners: results of an international survey. Eur Arch Psychiatry Clin Neurosci 2015;265:189-197.

63. Addington J, Heinssen RK, Robinson DG, et al. Duration of untreated psychosis in community treatment settings in the United States. Psychiatr Serv 2015:66:753-756.

64. Callus E, Pravettoni G. The role of clinical psychology and peer to peer support in the management of chronic medical conditions-a practical example with adults with congenital heart disease. Front Psychol 2018 ; 9:731.

65. Kazantzaki E, Kondylakis H, Koumakis L, et al. Psycho-emotional tools for better treatment adherence and therapeutic outcomes for cancer patients. Stud Health Technol Inform 2016;224:129-134.

66. Lapidari P, Djehal N, Havas J, et al. Determinants of use of oral complementary-alternative medicine among women with early breast cancer: a focus on cancer-related fatigue. Breast Cancer Res Treat 2021;190: 517-529.

67. McCambridge J, Witton J, Elbourne DR. Systematic review of the Hawthorne effect: new concepts are needed to study research participation effects. J Clin Epidemiol 2014;67:267-277.

68. Zigmond AS, Snaith RP. The Hospital Anxiety and Depression Scale. Acta Psychiatr Scand 1983;67:361-370.

69. Bjelland I, Dahl AA, Haug TT, et al. The validity of the Hospital Anxiety and Depression Scale: an updated literature review. J Psychosom Res 2002;52:69-77. 
Supplemental online content for:

\section{Uptake of Recommendations for Posttreatment Cancer-Related Fatigue Among Breast Cancer Survivors}

Antonio Di Meglio, MD, PhD; Cecile Charles, PhD; Elise Martin, PhD; Julie Havas, MSc; Arnauld Gbenou, MSc; Jean-Daniel Flaysakier, MD; Anne-Laure Martin, PhD; Sibille Everhard, PhD; Enora Laas, MD; Nicolas Chopin, MD; Laurence Vanlemmens, MD; Christelle Jouannaud, MD; Christelle Levy, MD; Olivier Rigal, MD; Marion Fournier, MD; Patrick Soulie, MD; Florian Scotte, MD; Barbara Pistilli, MD; Agnes Dumas, PhD; Gwenn Menvielle, PhD; Fabrice André, MD, PhD; Stefan Michiels, PhD; Sarah Dauchy, MD; and Ines Vaz-Luis, MD, PhD

J Natl Compr Canc Netw, doi: 10.6004/jnccn.2021.7051

eFigure 1: Proportion of Patients Consulting With a Psychologist and Psychiatrist by CRF and Psychologic Distress Status

eTable 1: Prevalence of Severe CRF Among Respondents Providing Data on Physical Activity and Consultations With Other HCPs

eTable 2: Sedentary Time by Severe Global CRF

eTable 3: Sensitivity Analyses of the Association Between Global CRF, Uptake of Physical Activity Recommendations, and Consultations With Other HCPs

eTable 4: Sensitivity Analyses of the Association Between Global CRF and CRF Dimensions, Uptake of Physical Activity Recommendations, and Consultations With Other HCPs

eAppendix 1: Supplementary Methods 
A

Psychology consultation rates by CRF and anxiety status

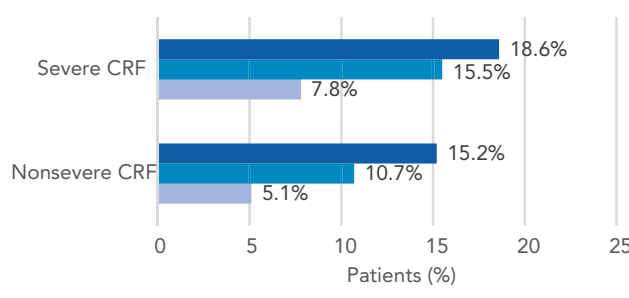

- Case - Doubtful $\mid$ Non-case

C

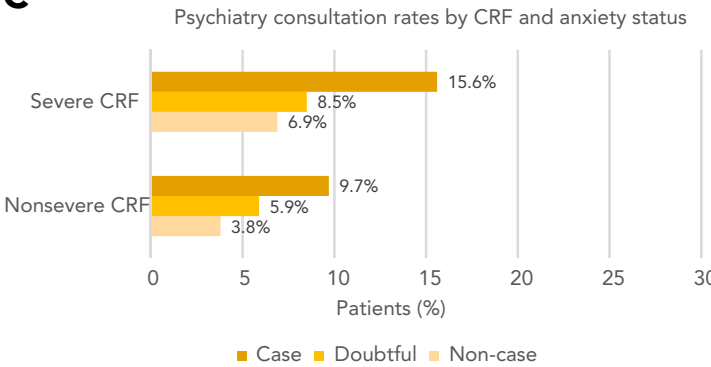

B

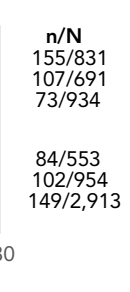

Psychology consultation rates by CRF and depression status

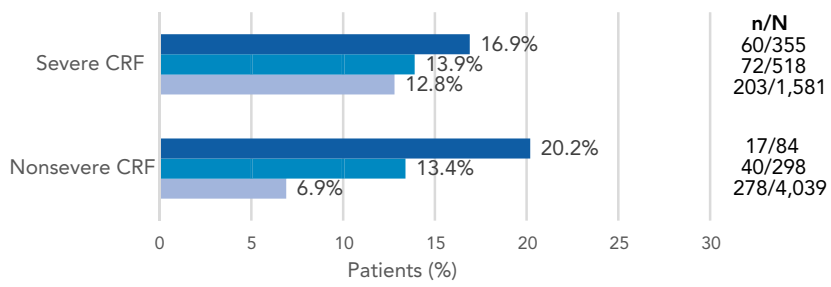

- Case - Doubtful $=$ Non-case

D

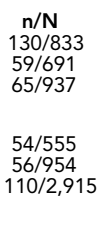

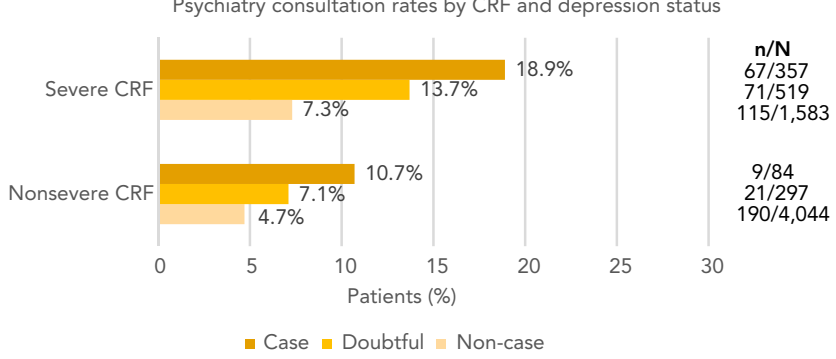

efigure 1. Proportion of patients consulting with a (A, B) psychologist and (C, D) psychiatrist by CRF and psychologic distress status (anxiety and depression, assessed using 2 separate subscales of the HADS). CRF and psychologic distress data were collected during the first posttreatment visit (after completion of primary treatment). Use of psychologic healthcare services (psychology and psychiatry consultations) was assessed over the course of the year following the CRF assessment.

Abbreviations: CRF, cancer-related fatigue; HADS, Hospital Anxiety and Depression Scale. 


\section{eTable 1. Prevalence of Severe CRF Among Respondents Providing Data on Physical Activity and} Consultations With Other HCPs

\begin{tabular}{|c|c|c|c|c|}
\hline & Global CRF & \multicolumn{3}{|c|}{ CRF Dimensions } \\
\hline \multicolumn{5}{|l|}{ Whole cohort with CRF data available } \\
\hline Mean [SD] & $36.2[25.7]$ & $33.2[24.3]$ & $23.3[26.5]$ & $18.0[23.4]$ \\
\hline Missing, $\mathrm{n}$ & - & 35 & 61 & 37 \\
\hline Reporting severe CRF, n/N (\%) & $2,217 / 6,263(35.4)$ & $2,176 / 6,239(34.9)$ & $1,338 / 6,222(21.5)$ & $837 / 6,239(13.4)$ \\
\hline Mean [SD] & $35.5[25.3]$ & $32.5[24.0]$ & $22.5[26.1]$ & $17.5[23.2]$ \\
\hline Missing, $n$ & - & 24 & 41 & 24 \\
\hline \multicolumn{5}{|l|}{ Psychology consultations respondents } \\
\hline Reporting severe CRF, n/N (\%) & $2,478 / 6,929(35.8)$ & $2,441 / 6,899(35.4)$ & $1,511 / 6,879(22.0)$ & $954 / 6,899(13.8)$ \\
\hline Reporting severe CRF, n/N (\%) & $2,484 / 6,939(35.8)$ & $2,445 / 6,909(35.4)$ & $1,515 / 6,889(22.0)$ & $655 / 6,909(9.5)$ \\
\hline Mean [SD] & 35.8 [25.5] & $32.9[24.1]$ & $22.8[26.3]$ & $17.8[23.2]$ \\
\hline Missing, $\mathrm{n}$ & - & 30 & 50 & 30 \\
\hline \multicolumn{5}{|c|}{ Acupuncture consultations respondents } \\
\hline Reporting severe CRF, n/N (\%) & $2,467 / 6,913(35.7)$ & $2,436 / 6,883(35.4)$ & $1,506 / 6,863(21.9)$ & $949 / 6,883(13.8)$ \\
\hline Mean [SD] & $35.8[25.5]$ & $32.9[24.1]$ & $22.8[26.3]$ & $17.8[23.2]$ \\
\hline Missing, $\mathrm{n}$ & - & 30 & 50 & 30 \\
\hline \multicolumn{5}{|l|}{ CAM consultations respondents } \\
\hline Reporting severe CRF, n/N (\%) & $2,467 / 6,913(35.7)$ & $2,436 / 6,883(35.4)$ & $1,506 / 6,863(21.9)$ & $949 / 6,883(13.8)$ \\
\hline
\end{tabular}

CRF data were collected during the first posttreatment visit (after completion of primary treatment). Physical activity and participation in consultations with other HCPs were assessed over the course of the year following the CRF assessment.

Abbreviations: CAM, complementary and alternative medicine; CRF, cancer-related fatigue; HCP, healthcare provider. 


\section{eTable 2. Sedentary Time by Severe Global CRF}

\begin{tabular}{|c|c|c|c|}
\hline & $\begin{array}{l}\text { Whole Cohort } \\
\text { Mean h/d }(95 \% \mathrm{Cl})\end{array}$ & $\begin{array}{l}\text { Insufficiently Active at } \\
\text { First Assessment } \\
\text { Mean h/d }(95 \% \mathrm{CI})\end{array}$ & $\begin{array}{l}\text { Sufficiently Active at } \\
\text { First Assessment } \\
\text { Mean h/d }(95 \% \mathrm{Cl})\end{array}$ \\
\hline Total, N & 6,263 & 2,280 & 3,983 \\
\hline \multicolumn{4}{|l|}{ Patients with nonsevere CRF } \\
\hline At first posttreatment visit & $5.57(5.31$ to 5.82$)$ & $6.09(5.64$ to 6.55$)$ & 5.26 (4.9 to 5.58$)$ \\
\hline Variation by second posttreatment visit & $+0.09(-0.04$ to +0.22$)$ & $+0.04(-0.21$ to +0.28$)$ & $+0.10(-0.05$ to +0.27$)$ \\
\hline \multicolumn{4}{|l|}{ Patients with severe CRF } \\
\hline At first posttreatment visit & 5.79 (5.53 to 6.05$)$ & $6.44(6.00$ to 6.87$)$ & 5.35 (5.02 to 5.67$)$ \\
\hline Variation by second posttreatment visit & $+0.13(-0.04$ to +0.32$)$ & $-0.07(-0.37$ to +0.22$)$ & $+0.30(+0.03$ to +0.51$)$ \\
\hline
\end{tabular}

Estimates are obtained using a multivariable-adjusted mixed model that includes CRF status, time, interaction time*CRF status, age, body mass index, comorbidities, anxiety and depression, education, income, tumor stage and subtype, breast cancer and axillary surgery, receipt of chemotherapy, center volume. Changes that were statistically significant have a $95 \%$ confidence interval around the mean change not crossing 0 . Models were first fit for the whole cohort and then separately among patients who were insufficiently or sufficiently active at first posttreatment assessment.

Abbreviation: CRF, cancer-related fatigue.

${ }^{a}$ CRF data were collected during the first posttreatment visit (after completion of primary treatment). Physical activity was assessed over the course of the year following the CRF assessment. 
eTable 3. Sensitivity Analyses of the Association Between Global CRF, Uptake of Physical Activity Recommendations, and Consultations With Other HCPs

\begin{tabular}{|c|c|c|c|c|c|}
\hline & $\begin{array}{l}\text { Maintained or } \\
\text { Increased } \\
\text { Physical Activity } \\
\text { aOR ( } 95 \% \mathrm{Cl})\end{array}$ & \multicolumn{4}{|c|}{ Other HCPs } \\
\hline $\mathrm{n} / \mathrm{N}(\%)$ & & $677 / 6,929(9.8 \%)$ & $479 / 6,939(6.9 \%)$ & $529 / 6,913(7.6 \%)$ & $675 / 6,913(9.8 \%)$ \\
\hline \multicolumn{6}{|c|}{ Sensitivity model A: inclusion of patient-reported outcomes ${ }^{a}$} \\
\hline \multicolumn{6}{|c|}{ Global CRF status ${ }^{b}$} \\
\hline Severe & $\begin{array}{l}0.84 \\
(0.72-0.98)\end{array}$ & $\begin{array}{l}1.10 \\
(0.87-1.38)\end{array}$ & $\begin{array}{l}1.36 \\
(1.05-1.77)\end{array}$ & $\begin{array}{l}1.22 \\
(0.95-1.57)\end{array}$ & $\begin{array}{l}1.39 \\
(1.11-1.73)\end{array}$ \\
\hline \multicolumn{6}{|c|}{ Pain (EORTC QLQ-C30) } \\
\hline Continuous & $\begin{array}{l}0.998 \\
(0.995-1.001)\end{array}$ & $\begin{array}{l}1.007 \\
(1.003-1.012)\end{array}$ & $\begin{array}{l}1.000 \\
(0.995-1.005)\end{array}$ & $\begin{array}{l}1.005 \\
(1.000-1.009)\end{array}$ & $\begin{array}{l}1.002 \\
(0.998-1.006)\end{array}$ \\
\hline \multicolumn{6}{|c|}{ Arm symptoms (EORTC QLQ-B23) ${ }^{\mathrm{b}}$} \\
\hline Continuous & $\begin{array}{l}1.000 \\
(0.997-1.002)\end{array}$ & $\begin{array}{l}1.001 \\
(0.997-1.005)\end{array}$ & $\begin{array}{l}1.000 \\
(0.995-1.004)\end{array}$ & $\begin{array}{l}1.001 \\
(0.996-1.005)\end{array}$ & $\begin{array}{l}1.002 \\
(0.998-1.006)\end{array}$ \\
\hline \multicolumn{6}{|c|}{ Sensitivity model b: inclusion of CTCAE toxicities ${ }^{a}$} \\
\hline \multicolumn{6}{|c|}{ Global CRF status $^{b}$} \\
\hline Nonsevere & Ref & Ref & Ref & Ref & Ref \\
\hline Severe & $\begin{array}{l}0.82 \\
(0.72-0.95)\end{array}$ & $\begin{array}{l}1.24 \\
(1.01-1.53)\end{array}$ & $\begin{array}{l}1.30 \\
(1.02-1.66)\end{array}$ & $\begin{array}{l}1.39 \\
(1.11-1.74)\end{array}$ & $\begin{array}{l}1.46 \\
(1.19-1.78)\end{array}$ \\
\hline \multicolumn{6}{|l|}{ Arthralgia ${ }^{b}$} \\
\hline No & Ref & Ref & Ref & Ref & Ref \\
\hline Any grade & $\begin{array}{l}0.97 \\
(0.86-1.10)\end{array}$ & $\begin{array}{l}1.09 \\
(0.90-1.33)\end{array}$ & $\begin{array}{l}1.04 \\
(0.83-1.30)\end{array}$ & $\begin{array}{l}1.05 \\
(0.85-1.29)\end{array}$ & $\begin{array}{l}1.32 \\
(1.09-1.59)\end{array}$ \\
\hline No & Ref & Ref & Ref & Ref & Ref \\
\hline Any grade & $\begin{array}{l}0.91 \\
(0.68-1.21)\end{array}$ & $\begin{array}{l}1.85 \\
(1.28-2.67)\end{array}$ & $\begin{array}{l}1.04 \\
(0.64-1.67)\end{array}$ & $\begin{array}{l}1.88 \\
(0.77-1.83)\end{array}$ & $\begin{array}{l}1.43 \\
(0.99-2.08)\end{array}$ \\
\hline
\end{tabular}

Abbreviations: AE, adverse effect; aOR, adjusted odds ratio; CAM, complementary and alternative medicine; CRF, cancer-related fatigue; EORTC QLQ, EORTC Quality of Life Questionnaire; HCP, healthcare provider.

${ }^{a}$ Models were also adjusted for age, body mass index, comorbidities, anxiety and depression, education, income, tumor stage and subtype, breast cancer and axillary surgery, receipt of chemotherapy, and center volume.

${ }^{b}$ Variables collected during the first posttreatment visit (after completion of primary treatment). Physical activity and participation in consultations with other HCPs were assessed over the course of the year following the CRF assessment. 


\section{eTable 4. Sensitivity Analyses of the Association Between Global CRF and CRF Dimensions, Uptake of Physical Activity Recommendations, and Consultations With Other HCPs}

\begin{tabular}{|c|c|c|c|c|c|}
\hline & \multirow{2}{*}{$\begin{array}{l}\text { Maintained or } \\
\text { Increased } \\
\text { Physical Activity } \\
\text { aOR }(95 \% \mathrm{Cl})\end{array}$} & \multicolumn{4}{|c|}{ Other HCPs } \\
\hline & & $\begin{array}{l}\text { Psychologist } \\
\text { aOR }(95 \% \mathrm{CI})\end{array}$ & $\begin{array}{l}\text { Psychiatrist } \\
\text { aOR }(95 \% \mathrm{Cl})\end{array}$ & $\begin{array}{l}\text { Acupuncturist } \\
\text { aOR }(95 \% \mathrm{CI})\end{array}$ & $\begin{array}{l}\text { CAM Practitioner } \\
\text { aOR }(95 \% \mathrm{Cl})\end{array}$ \\
\hline Event rate, n/N (\%) & $\begin{array}{l}4,035 / 6,263 \\
(64.4 \%)\end{array}$ & $\begin{array}{l}677 / 6,929 \\
(9.8 \%)\end{array}$ & $\begin{array}{l}479 / 6,939 \\
(6.9 \%)\end{array}$ & $\begin{array}{l}529 / 6,913 \\
(7.6 \%)\end{array}$ & $\begin{array}{l}675 / 6,913 \\
(9.8 \%)\end{array}$ \\
\hline \multicolumn{6}{|l|}{ Model A: global CRF } \\
\hline \multicolumn{6}{|l|}{ Global CRF ${ }^{b}$} \\
\hline Continuous & $\begin{array}{l}0.996 \\
(0.993-0.998)\end{array}$ & $\begin{array}{l}1.009 \\
(1.004-1.013)\end{array}$ & $\begin{array}{l}1.009 \\
(1.004-1.013)\end{array}$ & $\begin{array}{l}1.010 \\
(1.006-1.014)\end{array}$ & $\begin{array}{l}1.007 \\
(1.003-1.011)\end{array}$ \\
\hline \multicolumn{6}{|c|}{ Model B: CRF dimensions ${ }^{a}$} \\
\hline \multicolumn{6}{|l|}{ Physical CRF ${ }^{\mathrm{b}}$} \\
\hline Continuous & $\begin{array}{l}0.993 \\
(0.989-0.997)\end{array}$ & $\begin{array}{l}1.006 \\
(1.000-1.011)\end{array}$ & $\begin{array}{l}1.006 \\
(1.000-1.013)\end{array}$ & $\begin{array}{l}1.004 \\
(0.998-1.010)\end{array}$ & $\begin{array}{l}1.000 \\
(0.0994-1.005)\end{array}$ \\
\hline \multicolumn{6}{|l|}{ Emotional CRF ${ }^{\mathrm{b}}$} \\
\hline Continuous & $\begin{array}{l}0.999 \\
(0.995-1.003)\end{array}$ & $\begin{array}{l}1.006 \\
(1.001-1.012)\end{array}$ & $\begin{array}{l}1.002 \\
(0.996-1.008)\end{array}$ & $\begin{array}{l}1.003 \\
(0.997-1.009)\end{array}$ & $\begin{array}{l}1.004 \\
(0.999-1.010)\end{array}$ \\
\hline \multicolumn{6}{|l|}{ Cognitive $\mathrm{CRF}^{\mathrm{b}}$} \\
\hline Continuous & $\begin{array}{l}1.005 \\
(1.000-1.008)\end{array}$ & $\begin{array}{l}1.002 \\
(0.997-1.007)\end{array}$ & $\begin{array}{l}1.009 \\
(1.004-1.015)\end{array}$ & $\begin{array}{l}1.006 \\
(1.001-1.012)\end{array}$ & $\begin{array}{l}1.003 \\
(0.998-1.008)\end{array}$ \\
\hline
\end{tabular}

Abbreviations: aOR, adjusted odds ratio; CAM, complementary and alternative medicine; CRF, cancer-related fatigue; HCP, healthcare provider.

${ }^{a}$ Models were adjusted for age, body mass index, comorbidities, anxiety and depression, education, income, tumor stage and subtype, breast cancer and axillary surgery, receipt of chemotherapy, and center volume.

${ }^{b}$ Variables collected during the first posttreatment visit (after completion of primary treatment). Physical activity and participation in consultations with other HCPs were assessed over the course of the year following the CRF assessment. 


\section{eAppendix 1. Supplementary Methods}

\section{Details of Questionnaires Used to Assess Physical Activity and Cancer-Related Fatigue GPAQ-16}

The WHO Global Physical Activity Questionnaire (GPAQ)-16 assesses physical activity in 3 different domains (work, transportation [travel to/from places] and leisure [eg, sports and fitness]), as well as sedentary behavior (ie, sitting or reclining including at work, at home, watching television, or traveling, but not including time spent sleeping). Activity was reported in metabolic equivalents of task (MET)-hours/week.

\section{EORTC QLQ-C30 and EORTC QLQ-FA12}

The EORTC Core Quality of Life Questionnaire (QLQ-C30) is a 30-item questionnaire with a 3-item global cancerrelated fatigue (CRF) subscale (ie, over the past week: "Did you need to rest?," "Have you felt weak," "Were you tired”), independently validated as separate fatigue measure. The EORTC QLQ-FA12 explores the physical (eg, lack of energy, exhaustion), emotional (eg, feelings of helplessness, frustration), and cognitive (eg, trouble thinking clearly, confusion) dimensions of CRF. ${ }^{1,2}$ Questionnaires provide 4-point Likert scale responses for each item: "not at all," "a little," "quite a bit," and "very much." All items are subsequently converted to a 0 to 100 scale using a standard scoring algorithm, where higher scores reflect greater symptom severity. A validated French version of EORTC QLQC30 and QLQ-FA12 is available in the CANTO study. ${ }^{3-6}$ CRF was categorized as severe if patients scored $\geq 40 .{ }^{7}$

\section{References}

1. Aaronson NK, Ahmedzai S, Bergman B, et al. The European Organization for Research and Treatment of Cancer QLQ-C30: a quality-of-life instrument for use in international clinical trials in oncology. J Natl Cancer Inst 1993;85:365-376.

2. Weis J, Tomaszewski KA, Hammerlid E, et al. International psychometric validation of an EORTC quality of life module measuring cancer related fatigue (EORTC QLQ-FA12). J Natl Cancer Inst 2017;109.

3. Vaz-Luis I, Cottu P, Mesleard C, et al. UNICANCER: French prospective cohort study of treatment-related chronic toxicity in women with localised breast cancer (CANTO). ESMO Open 2019:4:e000562.

4. Sprangers MA, Groenvold M, Arraras JI, et al. The European Organization for Research and Treatment of Cancer breast cancer-specific quality-of-life questionnaire module: first results from a three-country field study. J Clin Oncol 1996;14:2756-2768.

5. Fayers P, Aaronson NK, Bjordal K, et al. The EORTC QLQ-C30 Scoring Manual, 3rd ed. Brussels, Belgium: European Organisation for Research and Treatment of Cancer; 2001.

6. Questionnaires. EORTC Quality of Life website. Accessed March 3, 2020. Available at: https://qol.eortc.org/questionnaires/

7. Abrahams HJG, Gielissen MFM, Schmits IC, et al. Risk factors, prevalence, and course of severe fatigue after breast cancer treatment: a meta-analysis involving 12327 breast cancer survivors. Ann Oncol 2016;27:965-974. 